\title{
Target detection in healthy 4-week old piglets from a passive two-tone auditory oddball paradigm
}

\author{
R. Anna Oeur ${ }^{1}$ and Susan S. Margulies ${ }^{1,2^{*}}$ (B)
}

\begin{abstract}
Background: Passive auditory oddball tests are effort independent assessments that evaluate auditory processing and are suitable for paediatric patient groups. Our goal was to develop a two-tone auditory oddball test protocol and use this clinical assessment in an immature large animal model. Event-related potentials captured middle latency P1, $\mathrm{N} 1$, and $\mathrm{P} 2$ responses in 4-week old ( $\mathrm{N}=16$, female) piglets using a custom piglet 32- electrode array on 3 non-consecutive days. The effect of target tone frequency $(250 \mathrm{~Hz}$ and $4000 \mathrm{~Hz})$ on middle latency responses were tested in a subset of animals.

Results: Results show that infrequent target tone pulses elicit greater N1 amplitudes than frequent standard tone pulses. There was no effect of day. Electrodes covering the front of the head tend to elicit greater waveform responses. P2 amplitudes increased for higher frequency target tones $(4000 \mathrm{~Hz})$ than the regular $1000 \mathrm{~Hz}$ target tones $(p<0.05)$.
\end{abstract}

Conclusions: Two-tone auditory oddball tests produced consistent responses day-to-day. This clinical assessment was successful in the immature large animal model.

Keywords: Auditory oddball paradigm, EEG, Event-related potential, Porcine

Highlights

- Two-tone auditory oddball tests were successfully assessed in an immature large animal model.

- Consistent N1, P2 amplitudes were observed across three non-consecutive test days.

- Infrequent target tone pulses elicited greater amplitude responses than frequent standard tone pulses.
*Correspondence: susan.margulies@emory.edu

2 Emory University, Health Sciences Research Building 1760 Haygood

Drive, Suite W242, 30322 Atlanta, Georgia

Full list of author information is available at the end of the article

\section{Background}

Approximately 283,000 children and adolescents ( $<18$ years old) visit the emergency department for a sports related traumatic brain injury (TBI) [1]. Considering the number of people who fail to seek medical care due to the seemingly 'mild' nature of some brain injury symptoms, the incidence of sports related TBI is likely much higher and has been estimated to be between 1.3 and 3.8 million [2]. The primary cause of non-fatal TBI for those 0-4 years old are from falls, and those 5-19 years old are from sport and recreation activities [3]. Mild TBI diagnosis relies on self-reported signs and symptoms and voluntary participatory assessments [4] resulting in greater challenges capturing accurate reporting and evaluation in the young paediatric population. There is heightened concern for mTBI in this age group due to the potential long-term neurological sequelae affecting cognition and behavior hindering learning and

(c) The Author(s) 2020. This article is licensed under a Creative Commons Attribution 4.0 International License, which permits use, sharing, adaptation, distribution and reproduction in any medium or format, as long as you give appropriate credit to the original author(s) and the source, provide a link to the Creative Commons licence, and indicate if changes were made. The images or other third party material in this article are included in the article's Creative Commons licence, unless indicated otherwise in a credit line to the material. If material is not included in the article's Creative Commons licence and your intended use is not permitted by statutory regulation or exceeds the permitted use, you will need to obtain permission directly from the copyright holder. To view a copy of this licence, visit http://creativeco mmons.org/licenses/by/4.0/. The Creative Commons Public Domain Dedication waiver (http://creativecommons.org/publicdomain/ zero/1.0/) applies to the data made available in this article, unless otherwise stated in a credit line to the data. 
development, thus supporting the need for objective biomarkers of mTBI that are not dependent upon patient reporting and effort [5].

Electroencephalography (EEG) is a promising tool in the study of neurological diseases as it measures the electrical potential of the brain on the millisecond scale and provides a real-time assessment of neural processes. Event related potentials (ERPs), measure brain-related activity in response to a stimulus and relates cerebral function with deficits and injury outcomes [6,7]. Auditory ERPs from infants and children in response to speech and sound processing have been correlated with the development of language suggesting that early differentiation of speech sounds have favorable associations with learning and reading capability [8-10]. In addition, auditory ERPs have been used as indices marking severe language impairment in children ages 9-15 years old in comparison to age matched controls [11]. Auditory oddball paradigms and ERPs are common tests used to elicit auditory processing at the cortical level [12, 13], and have been used as a marker of altered cognition in various diseased populations including concussion [14], schizophrenia [15] and autism [16]. These tests are effort independent tests that present infrequent 'target' tone pulses amongst a series of more frequent 'standard' tone pulses. Typically, the target tone elicits greater electrical potentials reflected as larger magnitude responses in comparison to the standard tones. Common response characteristic of the auditory oddball paradigm reflected in the EEG waveform are a series of positive peaks $(\mathrm{P})$ and negative troughs $(\mathrm{N})$ subsequently labelled in ascending temporal order (P1, N1, P2) or based on time course (P50 at $50 \mathrm{~ms}$ ). Auditory stimulation causes an early positive peak, P1 or P50 around $50 \mathrm{~ms}$ and is associated with an orientation to a new sound, not yet influenced by attention. What follows is a negative peak around $100 \mathrm{~ms}$ (N1), thought to be associated with early attention and related to detecting sensory changes. A second positive peak at $200 \mathrm{~ms}$ (P2) is also considered to be involved in early attention $[12,13]$.

Findings in the literature for concussed patient groups have reported attenuated amplitudes and longer latency responses in comparison to a healthy cohort [17]. The on-going hypothesis is that the altered brain is unable to mobilize attentional resources to elicit similar magnitude responses (reduced amplitudes) and longer latencies indicate slower processing speeds [12]. Research findings have not been congruent across studies where some have demonstrated no differences in ERPs between injured and healthy cohorts, which may be a result of subtleties in the auditory oddball paradigm employed [14]. Passively listening to tones versus more complex oddball tasks requiring active participation through counting or pressing a button at the presentation of a target stimulus can involve different auditory pathways [18]. Despite more complex tasks revealing subtleties in auditory deficits after mTBI $[19,20]$, these participatory assessments may present an added challenge in the paediatric patient.

In addition to non-uniform test protocols and stimulus paradigms employed across studies, diverse findings can also be attributed to participant ages, sample sizes and the mechanisms or causes of head trauma [21, 22]. The mechanism of injury plays a primary role in the patterns of trauma where biomechanical characteristics such as the direction of head movement and relative levels of head rotation influence the nature and distribution of neural tissue traumas and subsequent injury outcomes $[23,24]$. Varying levels of these injury factors likely contribute to the specific brain structures and functions that result in diverse signs and symptoms associated with mTBI, possibly leading to sub-types of concussion [25].

Preclinical animal models allow control of a number of factors, including biomechanical loading characteristics that permit systematic evaluation of structural, functional, and behavioural outcomes. Pigs are a common large animal model used to study neurological disorders and TBI $[26,27]$. The 4-week old piglet brain is an established model of paediatric TBI and has been previously used to study diffuse axonal injury and intracranial haemorrhage $[28,29]$. The anatomy of the pig brain contains similar distributions of white and grey matter, in addition to well-formed sulci and gyri that are key to modelling the human brain $[30,31]$. The maturation trajectory of piglet brains are also similar to the young human brain with the 3-4 week old and 3 month old piglet paralleling the child and adolescent brain [32-34].

The objective of this study is to establish the auditory oddball response, a common study paradigm used in humans, in the 4-week old piglet model to benchmark auditory processing in a healthy cohort. It is hypothesized that P1, N1, P2 features will be observable in the waveform responses, and that the infrequent randomized target tones produce a greater response than the frequent standard tones. A second objective was to examine the effect of target tone frequency. In a separate set of tests, the frequency of the target tone was four times lower $(250 \mathrm{~Hz})$ or higher $(4000 \mathrm{~Hz})$ than the regular target tone $(1000 \mathrm{~Hz})$. The standard tone in all cases was $800 \mathrm{~Hz}$. It is hypothesized that the greater the $4000 \mathrm{~Hz}$ target tone would produce a greater P1, N1, and P2 amplitudes than the 250 and $1000 \mathrm{~Hz}$ target tones.

\section{Methods}

All procedures were approved by the Institutional Animal Care and Use Committee (IACUC) at Emory University School of Medicine. Experiments were carried out in 
an AAALAC International (Association for Assessment and Accreditation of Laboratory Animal Care) accredited facility. Sixteen 4-week-old female Yorkshire piglets (Sus Sus scrofa) were acquired from a commercial vendor, Palmetto Research Swine (South Carolina, USA) and were studied in this research to understand auditory processing in a healthy cohort. The animals were housed in groups of two to four in metal enclosures with plastic slated floors to allow for socialization. All animals were on a 12-h light and 12-h dark cycle and permitted ad libitum access to mini pig start diet (LabDiet 5080, St. Louis, MO) and water. All data collection was performed in a separate test room that housed all necessary equipment. Prior to auditory tests, animals were acclimated to the test room, sling, and a nylon stocking to simulate the EEG net. Acclimation was repeated on two separate days. On test days, animals were taken one at a time into the test room, placed in a sling, and were closely monitored and supported by two research staff.

EEG were collected using a custom-built 32-electrode Hydrocel Geodesic Sensor Net (GSN), originally designed for use on humans, that recorded scalp electrical activity during auditory stimuli (Electric Geodesics Inc., EGI, Eugene, OR). The electrode net is an elastomer structure with embedded chambers containing a single electrode and sponge, with room for eyes and ears and adjustable chinstraps to ensure a close fit. A computer cart with a Hypertronics connector arm links the 32-electrode net to the Net Amps 400 amplifier (Electric Geodesics Inc., EGI, Eugene, OR) and houses the data acquisition and stimulus presentation computers. Data acquisition was accomplished using a MacBook Pro laptop with Netstation 5.0 software (Electric Geodesics Inc., EGI, Eugene, OR) synchronized to a PC computer with
E' Prime 2.0 (Psychology Software Tools, Inc, Pittsburgh, PA) stimulus presentation software. A portable speaker connected to the PC computer via audio jack played the auditory stimuli at a distance of approximately $0.5 \mathrm{~m}$ from the top and centre of the piglets head. Prior to testing, the electrode net was soaked in a solution of baby shampoo $(5 \mathrm{~mL})$ and potassium chloride $(10 \mathrm{~mL})$ mixed in $1 \mathrm{~L}$ of water for at least $5 \mathrm{~min}$. The net was then applied to the surface of the animal's head and electrical impedance for all electrodes was checked to be below $1 \mathrm{k} \Omega$. A light nylon stocking with holes cut out for ears and eyes was fitted over the electrode net to maintain scalp contact throughout data collection.

\section{Part A-regular oddball clicktrain}

EEG data was collected for each animal in response to an auditory oddball paradigm comprised of 100 tone pulses with each pulse lasting $2 \mathrm{~ms}$ and an inter-stimulus interval of $280 \mathrm{~ms}$. The 'regular' oddball clicktrain was comprised of 70 standard $800 \mathrm{~Hz}$ tone pulses and 30 target $1000 \mathrm{~Hz}$ tone pulses played in random order (Fig. 1). Each 100-pulse clicktrain lasted approximately $30 \mathrm{~s}$ and was repeated for each animal to obtain 6 good trials. Twelve piglets $(\mathrm{N}=12)$ were tested according to the 'regular' oddball click train for three non-consecutive days of testing.

\section{Part B-alternative target pulse clicktrain}

A subset of six animals (out of twelve from Part A) were played an alternative clicktrain on a fourth day where the pitch of the target was either a low $250 \mathrm{~Hz}$ target tone pulse ( 3 animals) or a high $4000 \mathrm{~Hz}$ target tone pulse (3 animals). Four additional animals were studied and subject to the regular oddball clicktrain, followed by a low

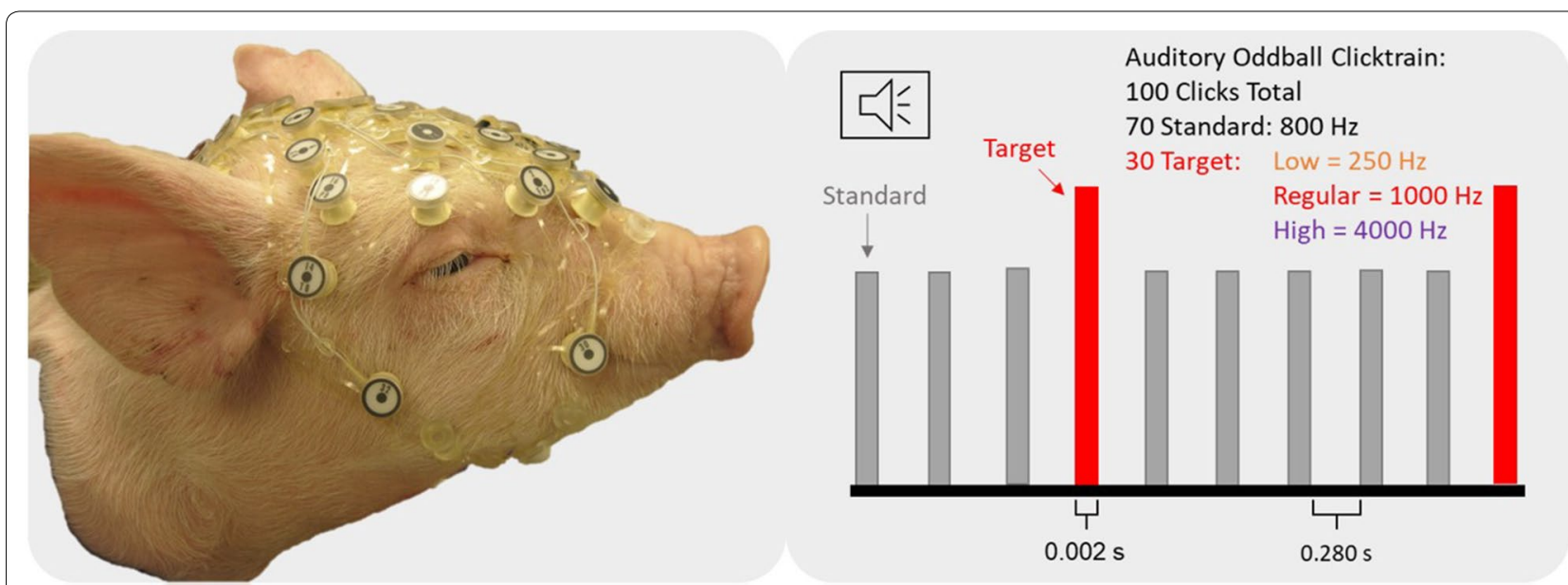

Fig. 1 Depiction of an animal fitted with the 32-electrode net (left) and a representation of the auditory oddball stimulus presentation sequence (right) 
target pulse click train (2 animals) or a high target pulse click train (2 animals). All of these tests occurred on the same day, where the regular oddball was played first, followed by the alterative oddball clicktrain to keep with a similar order as the subset of six animals studied from Part A. In total, five animals were tested according to regular and low target $(\mathrm{N}=5)$ pulse clicktrains and five animals were tested with regular and high target $(\mathrm{N}=5)$ pulse clicktrains. All animal data from both the regular and the alternative oddball click trains were processed and there were no exclusions from analysis. All animals were euthanized within 3 days after the last study day with an overdose of pentobarbital (Euthasol $1 \mathrm{~mL} / 10 \mathrm{lb}$ of body weight) via an intracardiac injection. Prior to the injection, all piglets were under general anaesthesia using isoflurane at a rate of $3-5 \%$ and the absence of a deep pain response was confirmed using a toe pinch.

\section{Data processing}

Data were processed using Netstation Tools (Electric Geodesics Inc., EGI, Eugene, OR) to filter (band pass: 0.1-30 Hz), segment (300 ms epochs; $50 \mathrm{~ms}$ before and $250 \mathrm{~ms}$ after stimulus), and to detect and replace bad channels $(>200 \mu \mathrm{V})$. Baseline correction, artefact detection and eye blink removal were completed via independent components analysis in EEGlab (Versio14.12; Delorme \& Makeig, 2004) and Matlab (Version: 2018b; The Mathworks, Inc., Natick, MA, USA; Onton, Westerfield, Townsend, \& Makeig, 2006). Waveform averaging, visualization, and peak extraction for each animal per day were also conducted in EEGlab and Matlab.

\section{Data analysis strategy}

EEG waveforms were examined to locate the first identifiable local maxima, followed by a local minima, and subsequent local maxima corresponding to the $\mathrm{P} 1, \mathrm{~N} 1$, and P2 peaks. Prior to peak amplitude extraction of $\mathrm{P} 1$, $\mathrm{N} 1$, and P2, grand waveform averages for all three days of testing per animal were examined to determine approximate latency widows for each peak. These latencies were then used to guide peak amplitude extraction for each animal per day for electrodes representing regions of the crown $(9,10,19,20)$, front $(1,2,3,4,17,27)$, left $(5,11$, $13,15)$, and right $(6,12,14,16,24)$ (Fig. 2). The amplitude and latency values for each group of electrodes were then averaged and used as input as a single value for statistical analysis.

\section{Statistical analysis \\ Part A-regular oddball clicktrain}

Three-way repeated measures ANOVAs evaluated the effects of "electrode group" (4 levels: front, crown, left and right), "tone type" (2 levels: standard and target)

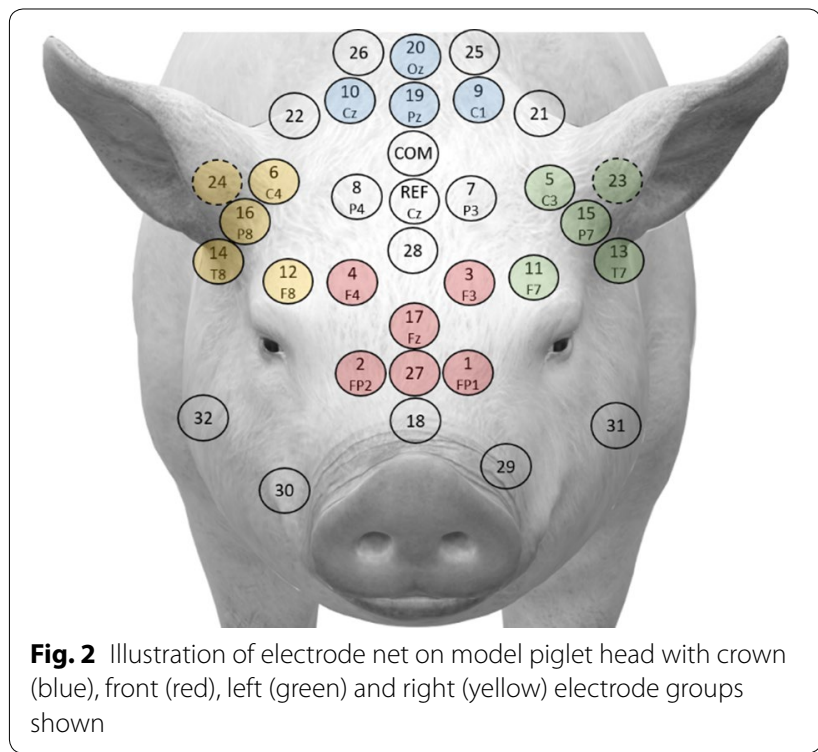

and the repeated factor of "day" (3 levels: day 1, 2, and 3) on P1, N1, and P2, and P1-N1 and N1-P2 peak-to-peak amplitudes and latencies. Post hoc analyses involved Bonferroni tests if variances were equal based on Mauchly's sphericity tests and Dunnett's T3 if variances were unequal.

\section{Part B-alternative target pulse clicktrain}

Paired t-tests for regular target pulse $(1000 \mathrm{~Hz})$ and alternative target pulse $(250 \mathrm{~Hz}$ or $4000 \mathrm{~Hz})$ were conducted on P1, N1, and P2, and P1-N1 and N1-P2 peak-to-peak amplitudes and latencies. All statistics were conducted using IBM SPSS Statistics Version 25 for Windows (Armonk, NY: IBM Corp.) and significance was accepted at $\mathrm{p}<0.05$.

\section{Results}

\section{Part A-regular oddball clicktrain}

Grand averages for target and standard waveforms are presented in Fig. 3. A single electrode is shown to represent the different electrode groups: 17 for front, 19 for crown, 13 and 14 for left and right, respectively. The N1 and P2 amplitudes had consistent negative and positive values however; distinguishable P1 local maxima were not always present or did not have a positive value across electrodes, animals, and test days (Fig. 3). Therefore, P1 values were not used in the statistical analysis and the dependent variables were limited to N1, P2, and N1-P2 peak-to-peak amplitudes and latencies.

A summary of amplitudes and latencies for healthy 4 week-old piglets across all three days tested is presented in Table 1 as means and standard deviations for each 


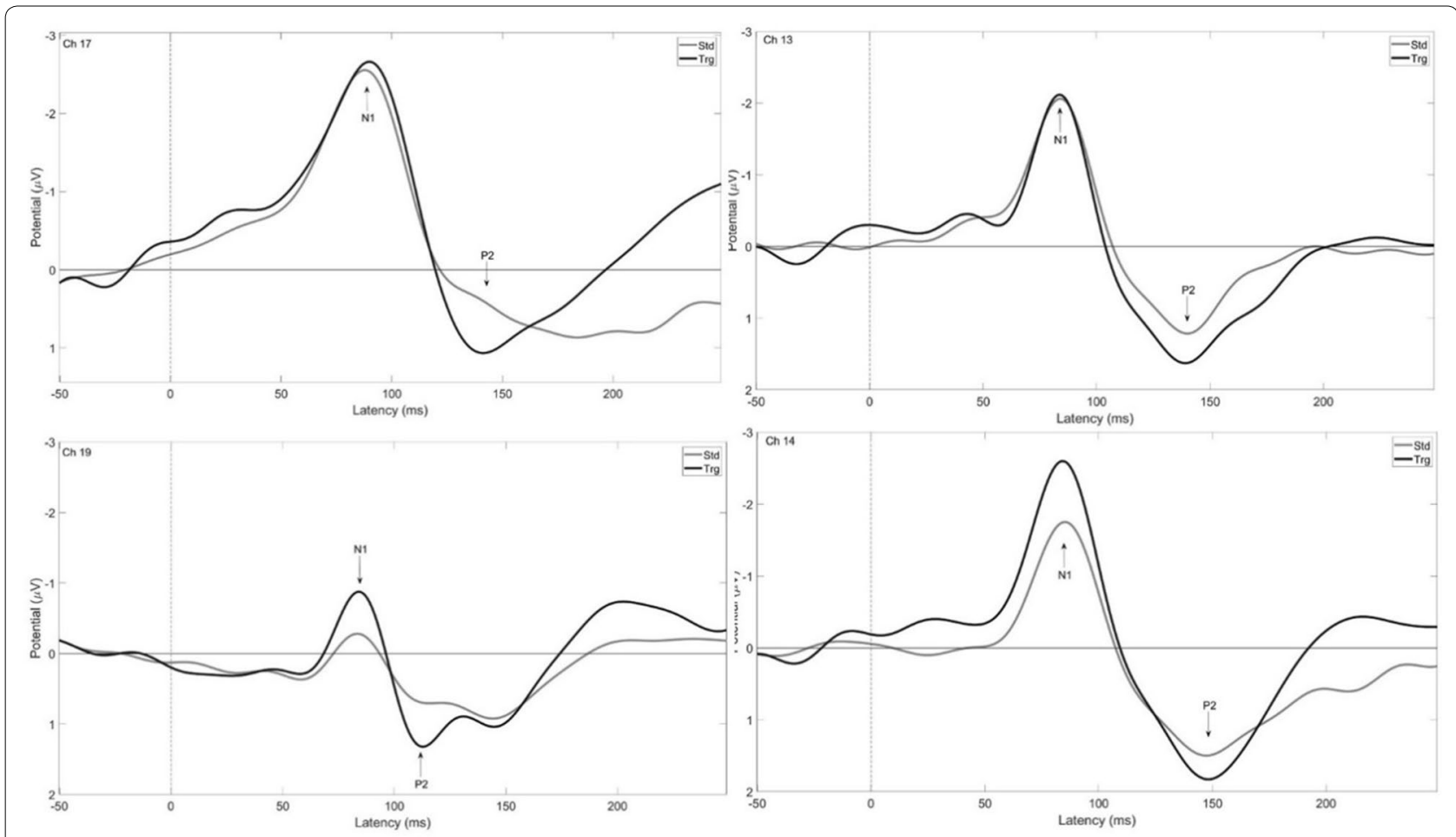

Fig. 3 Grand averages depicting waveforms for target (black) and standard (gray) tones for single channels representing the front (Ch 17), crown (Ch 19), left (Ch 13), and right (Ch 14) for regular auditory oddball tests

electrode group. There were significant main effects for tone type $\left(\mathrm{F}(1,11)=5.4, \mathrm{p}=0.041, \eta \mathrm{p}^{2}=0.328\right)$ and electrode group $\left(\mathrm{F}(1.8,20.1)=30.7, \mathrm{p}<0.01, \eta \mathrm{p}^{2}=0.736\right)$ for N1 amplitudes and N1-P2 amplitudes (electrode group: $\left(\mathrm{F}(3,33)=22.9, \mathrm{p}<0.01, \mathrm{np}^{2}=0.675\right.$; tone type: $\left(\mathrm{F}(1,11)=18.3, \mathrm{p}=0.001, \eta \mathrm{p}^{2}=0.624\right)$. Post hoc analyses revealed similar effects for both dependent variables, where the crown had the lowest values, followed by the left and right regions, which were not significantly different from each other, and the front electrodes had the largest values $(\mathrm{p}<0.05)$. For tone type, target tones produced greater amplitudes than standard tones $(\mathrm{p}<0.05)$. Similarly for peak latencies, there was a significant main effect of electrode group $\left(\mathrm{F}(3,33)=14.7, \mathrm{p}<0.01, \eta \mathrm{p}^{2}=\right.$ $0.571)$ on P2 latency and N1-P2 latency $(\mathrm{F}(3,33)=16.7$, $\left.\mathrm{p}<0.01, \eta \mathrm{p}^{2}=0.603\right)$. Post hoc analyses revealed that the crown had the shortest latencies, followed by left and right regions, and front with the longest latencies ( $\mathrm{p}$ $<0.05$ ). A depiction of significant results are shown in Fig. 4.

\section{Part B-alternative target pulse clicktrain}

Grand averages for low, regular, and high target waveforms are presented in Fig. 5. A single electrode is shown to represent the different electrode groups: 17 for front, 19 for crown, 13 and 14 for left and right, respectively.
A summary of amplitudes and latencies for low and high target tones are presented in Table 2 as means and standard deviations for each electrode group. Based on the findings from Part $A$, the statistical analyses were limited to N1, P2, and N1-P2 peak-to-peak amplitudes and latencies for target tones. Low target tones $(250 \mathrm{~Hz})$ did not produce significantly different results than target tones in the regular tests $(1000 \mathrm{~Hz})$, however high target tones $(4000 \mathrm{~Hz})$ were found to produce significantly greater P2

Table 1 Summary table of means and standard deviations of $\mathrm{N} 1$ and $\mathrm{P2}$ amplitudes $(\mu \mathrm{V})$ and latencies (ms) for the target and standard tones across electrode groups

\begin{tabular}{|c|c|c|c|c|c|}
\hline & \multirow{2}{*}{$\begin{array}{l}\text { Electrode } \\
\text { group }\end{array}$} & \multicolumn{2}{|c|}{ Amplitude $(\mu \mathrm{V})$} & \multicolumn{2}{|c|}{ Latency (ms) } \\
\hline & & Target & Standard & Target & Standard \\
\hline \multirow[t]{4}{*}{ N1 } & Front & $-3.5(2.0)$ & $-2.9(1.5)$ & $92.1(11.8)$ & $89.2(11.2)$ \\
\hline & Crown & $-1.0(1.3)$ & $-0.6(0.9)$ & $87.0(13.1)$ & $88.0(15.7)$ \\
\hline & Left & $-2.0(1.3)$ & $-1.8(1.2)$ & $93.5(12.9)$ & $91.6(13.4)$ \\
\hline & Right & $-2.3(1.5)$ & $-1.7(1.1)$ & $91.7(17.4)$ & $90.3(16.4)$ \\
\hline \multirow[t]{4}{*}{ P2 } & Front & $2.0(2.2)$ & $1.5(1.3)$ & 147.9 (18.3) & 150.5 \\
\hline & Crown & $1.7(1.4)$ & $1.1(1.1)$ & $124.4(13.3)$ & $128.9(19.6)$ \\
\hline & Left & $2.1(1.8)$ & $1.6(1.3)$ & $140.1(17.7)$ & $139.3(20.3)$ \\
\hline & Right & $2.1(1.7)$ & $1.7(1.2)$ & $138.3(20.8)$ & $137.4(24.2)$ \\
\hline
\end{tabular}



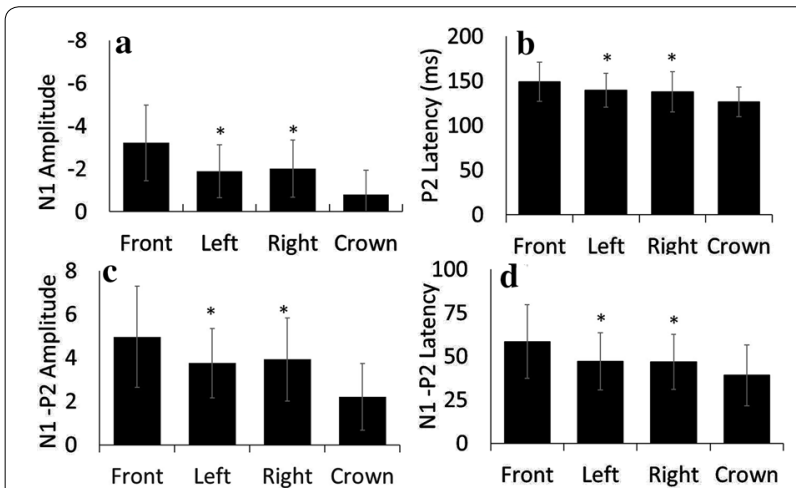

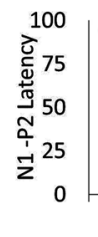
Front
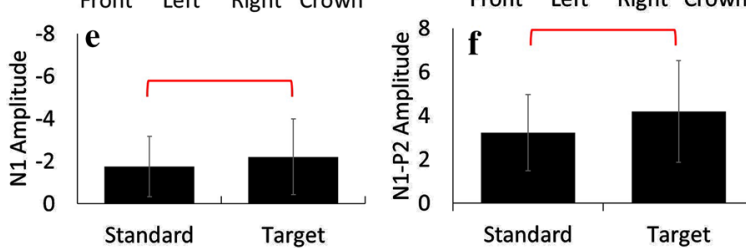

Fig. 4 Significant findings for electrode group with N1 amplitude (a), P2 latency (b), and N1-P2 amplitude (c) and latency (d). All comparisons were statistically significant except where ${ }^{\prime * \prime}$ denotes statistically similar results. Significant findings for tone type are illustrated for N1 (e) and N1-P2 (f) amplitudes with significant differences are illustrated with an overlaying bar amplitudes (Fig. 6) than regular target tones $(1000 \mathrm{~Hz})$ for the right electrode group $(t[4]=-4.03, p=0.016)$.

\section{Discussion}

A two-tone auditory oddball paradigm was used to characterize ERPs in healthy 4-week old piglets. N1 and P2 local minima and maxima were the two features of the electrical potential waveform that had consistent negative and positive values occurring at N90 (82-92 ms) and P140 (124-150 ms), respectively. It is possible that these waveform responses are congruent to the $\mathrm{N} 130$ at $132 \mathrm{~ms}$ and the P160 at $156 \mathrm{~ms}$ reported for a two-tone auditory oddball paradigm studied in older (12-14 months) male Gottigen minipigs [37]. In the 4-week old piglets studied here, infrequent target stimuli elicited greater waveform responses than frequent standard tones. This is in accordance with findings reported by Arnfred, Lind [37] for older male minipigs, and also in children 4-13 years old [16, 38] and adults [18] for passive listening to an auditory oddball paradigm.

Regional differences were observed for $\mathrm{N} 1$ and P2 responses as noted by the averaged values for each electrode group. Electrodes capturing activity at the front had the greatest waveform responses, followed by the right and left regions, with the crown region demonstrating the smallest waveforms. These findings are consistent with those found in humans, where the fronto-central

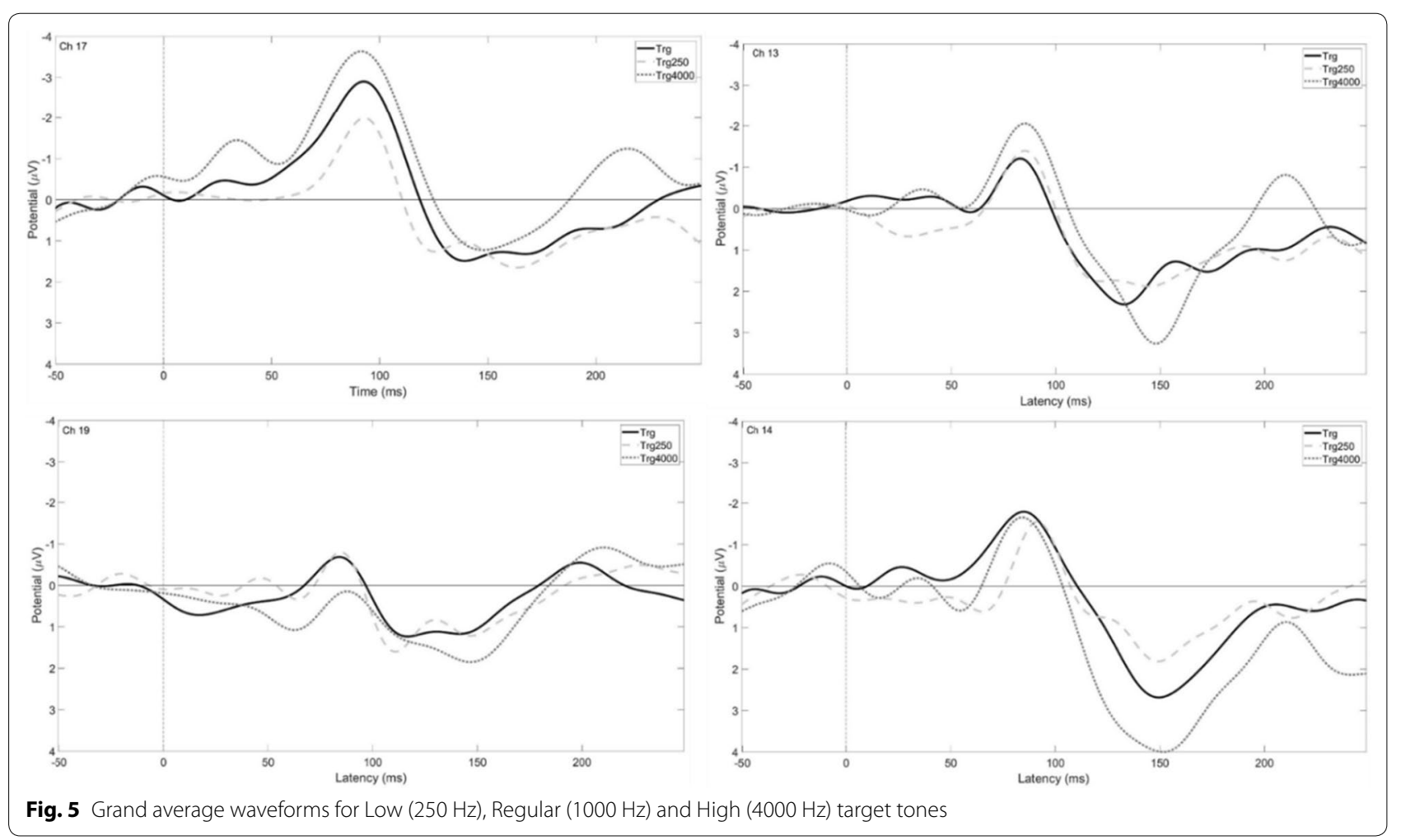


Table 2 Summary table of means and standard deviations of N1 and P2 amplitudes ( $\mu \mathrm{V})$ and latencies (ms) for the low and high target tones across electrode groups

\begin{tabular}{|c|c|c|c|c|c|}
\hline & \multirow[t]{2}{*}{ Electrode group } & \multicolumn{2}{|c|}{ Amplitude $(\mu \mathrm{V})$} & \multicolumn{2}{|l|}{ Latency (ms) } \\
\hline & & Low $(250 \mathrm{~Hz})$ & High $(4000 \mathrm{~Hz})$ & Low $(250 \mathrm{~Hz})$ & High $(4000 \mathrm{~Hz})$ \\
\hline \multirow[t]{4}{*}{$\mathrm{N} 1$} & Front & $-2.8(1.7)$ & $-3.3(1.4)$ & $96.2(4.9)$ & $90.4(7.3)$ \\
\hline & Crown & $-0.7(1.7)$ & $-0.1(1.1)$ & $92.8(16.3)$ & $87.4(3.5)$ \\
\hline & Left & $-1.7(1.4)$ & $-1.8(1.4)$ & $92.8(23.0)$ & $93.9(9.0)$ \\
\hline & Right & $-1.8(1.2)$ & $-1.2(0.7)$ & $98.7(7.4)$ & $89.7(11.8)$ \\
\hline \multirow[t]{4}{*}{ P2 } & Front & $1.4(0.6)$ & $3.2(1.3)$ & $155.6(10.6)$ & $157.1(30.2)$ \\
\hline & Crown & $1.7(1.2)$ & $2.2(1.1)$ & $132.4(23.2)$ & $135.3(15.3)$ \\
\hline & Left & $1.8(1.1)$ & $3.4(1.4)$ & $151.0(24.2)$ & $156.9(26.6)$ \\
\hline & Right & $2.0(0.8)$ & $4.0(1.2)$ & $155.3(12.9)$ & $146.8(13.0)$ \\
\hline
\end{tabular}

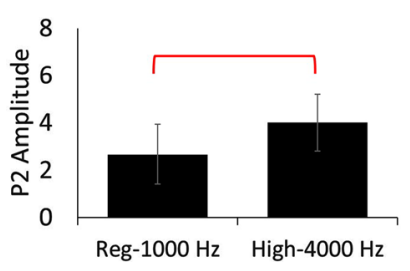

Fig. 6 P2 amplitude results for regular $1000 \mathrm{~Hz}$ target tone and high $4000 \mathrm{~Hz}$ target tone for the front electrode group. Significance is indicated with an overlaying bar

region reflected the greatest activity for target tones in an auditory oddball paradigm [13, 14, 18]. Similarly, this finding was also consistent in older (12-14 month) male Gottingen minipigs where frontal channels demonstrated greater activity than posterior channels [39]. Activity observed in the left and right electrode groups in this study may be reflective of involvement of the early central auditory pathways and auditory cortex in response to the identification and perception of sound [12]. The left and right electrode groups are regions close to the ears and auditory cortex where auditory regions have been reported to be located near the lateral fissure in miniature swine [40]. Reduced activity at the crown is likely due to the electrodes covering this region are located behind the ears and toward the back of the neck. It is unlikely that cortical activity related to auditory processing are detected in this area (Fig. 2).

Regular auditory oddball tests were collected for three non-consecutive days for each animal in this cohort. There were no significant main effects of test day; therefore, two-tone auditory oddball tests elicit consistent day-to-day responses and these methods area repeatable in 4-week old piglets. Furthermore, results from the alternative target tone tests showed that modifying the pitch of the target tone was not found to influence the $\mathrm{N} 1$ amplitudes; however, the higher $4000 \mathrm{~Hz}$ target tones produced greater P2 amplitudes than the $1000 \mathrm{~Hz}$ target tones. Like the N1, the P2 has also been associated with early attention allocation and is also considered a reliable indicator of auditory stimulus processing in humans [12].

A direct limitation of this study are that ERP data were extracted from a subset of 20 electrodes from the total 32 that were concurrently used to collect EEG. The method of peak amplitude and latency extraction corresponding to $\mathrm{N} 1$ and $\mathrm{P} 2$ features of the middle latency response are common to the greater auditory processing literature, however, due to the complexity of neural processes and cognition, these results may only capture a single aspect of multifaceted auditory processing. In addition, age specific responses have been noted in the human literature where the amplitude and latency responses are a function of age and brain maturation, where responses for adults are unique from infants, children, and adolescent age groups [41-43]. It is likely that auditory responses in piglets are similarly affected by age and maturational processes, therefore, these findings are specific to the 4-week old piglet. The 4-week old piglet is a common animal model used to represent traumatic brain injury in children due to parallels in brain composition during early development $[30,33,44]$.

\section{Conclusions}

An auditory oddball paradigm elicited consistent N1 and P2 middle latency responses in healthy 4-week old piglets. Infrequent target tones elicited greater N1 and N1-P2 amplitudes than standard tones, which is in alignment with other pig studies and the human literature for children and adults. Greater activity toward the front electrode group in 4-week old piglets is consistent with maximal fronto-central activity associated with auditory deviant sound processing in humans. There 
were no effects of test day; therefore, two-tone auditory oddball tests elicit consistent day-to-day responses. This clinical assessment was successful in the immature large animal model.

\begin{abstract}
Abbreviations
AAALAC: Association for Assessment and Accreditation of Laboratory Animal Care; EEG: Electroencephalography; ERP: Event-Related Potential; GSN: Geodesic Sensor Net; IACUC: Institutional Animal Care and Use Committee; mTBI: Mild Traumatic Brain Injury; TBI: Traumatic Brain Injury.
\end{abstract}

\section{Acknowledgements}

Not applicable.

\section{Authors' contributions}

Both authors made substantial contributions to the paper and contributed to the conception and design, and interpretation of data. RAO ran the experiments, collected and analysed the data. RAO and SSM interpreted the data. Manuscript draft and revisions were completed by both RAO and SSM. Both authors read and approved the final manuscript.

\section{Funding}

The research was supported by a grant awarded to SSM by the National Institutes of Health (NIH) Grant Number: R01NS097549 and the Georgia Research Alliance. The grant supported the necessary funds for acquiring study animals and salaries for veterinary personnel and support staff for data collection and analysis. The sponsors were not involved in the design, methods, data collection, analysis, or preparation of this paper.

\section{Availability of data and materials}

The datasets used and/or analysed during the current study are available from the corresponding author on reasonable request.

\section{Ethics approval and consent to participate}

All procedures were approved by the Institutional Animal Care and Use Committee (IACUC) at Emory University School of Medicine. Experiments were carried out in an AAALAC (Association for Assessment and Accreditation of Laboratory Animal Care) accredited facility.

\section{Consent for publication}

Not applicable.

\section{Competing interests}

The authors declare that they have no competing interests.

\section{Author details}

${ }^{1}$ Wallace H. Coulter Department of Biomedical Engineering, Emory University, 615 Michael St. Suite 655, Atlanta, GA, USA. ${ }^{2}$ Emory University, Health Sciences Research Building 1760 Haygood Drive, Suite W242, 30322 Atlanta, Georgia.

Received: 29 June 2020 Revised: 6 November 2020 Accepted: 16 November 2020

Published online: 07 December 2020

\section{References}

1. Sarmiento K, Thomas KE, Daugherty J, Waltzman D, Haarbauer-Krupa JK, Peterson AB, et al. Emergency Department Visits for Sports- and Recreation-Related Traumatic Brain Injuries Among Children — United States, 2010-2016. MMWR Morbidity Mortality Wkly Re. 2019;68(10):237-42.

2. Langlois JA, Rutland-Brown W, Wald MM. The epidemiology and impact of traumatic brain injury: a brief overview. J Head Trauma Rehabil. 2006;21(5):375-8.

3. Ali B, Lawrence BA, Miller T, Allison J. Products and activities associated with non-fatal traumatic brain injuries in children and adolescents United States 2010-2013. Brain Inj. 2019;33(11):1425-9.
4. McCrory P, Meeuwisse W, Dvorak J, Aubry M, Bailes J, Broglio S, et al. Consensus statement on concussion in sport-the 5th international conference on concussion in sport held in Berlin, October 2016. Br J Sports Med. 2017;51(11):838-47.

5. Lumba-Brown A, Yeates KO, Sarmiento K, Breiding MJ, Haegerich TM, Gioia GA, et al. Diagnosis and management of mild traumatic brain injury in children: a systematic review. JAMA Pediatric. 2018:8:999.

6. Luck SJ, Mathalon DH, O'Donnell BF, Hmlinen MS, Spencer KM, Javitt DC, et al. A roadmap for the development and validation of eventrelated potential biomarkers in schizophrenia research. Biol Psychiatry. 2011;70(1):28-34.

7. Rappaport M, Hall K, Hopkins K, Belleza T, Berrol S, Reynolds G. Evoked brain potentials and disability in brain-damaged patients. Arch Phys Med Rehabil. 1977;58(8):333-8.

8. Molfese DL, Molfese VJ, Key AF, Kelly SD. Influence of environment on speech-sound discrimination: findings from a longitudinal study. Develop Psychol. 2003;24(2-3):541-58.

9. Simos PG, Molfese DL. Electrophysiological responses from a temporal order continuum in the newborn infant1The authors wish to thank Dr. David Pisoni who generously provided the TOT stimuli. The assistance of Rebecca Brenden and Angela Russel during data collection is gratefully acknowledged. This research was supported in part from a grant from the National Institutes of Health (RO1 HD17860).1. 1997;35(1):89-98.

10. Tan AA, Molfese DL. ERP correlates of noun and verb processing in preschool-age children. Biol Psychol. 2009;80(1):46-51.

11. Tonnquist-Uhlén I, Borg E, Persson HE, Spens KE. Topography of auditory evoked cortical potentials in children with severe language impairment: the N1 component. Electroencephalogr Clin Neurophysiol. 1996;100(3):250-60.

12. Washnik NJ, Anjum J, Lundgren K, Phillips S. A review of the role of auditory evoked potentials in mild traumatic brain injury assessment. Trends Hear. 2019;23:1-13.

13. Näätänen R, Picton T. The N1 wave of the human electric and magnetic response to sound: a review and an analysis of the component structure. Psychophysiology. 1987;24(4):375-425.

14. Vander Werff KR, Rieger B. Impaired auditory processing and neural representation of speech in noise among symptomatic post-concussion adults. Brain Inj. 2019;33(10):1320-31.

15. Javitt DC, Grochowski S, Shelley A-M, Ritter W. Impaired mismatch negativity (MMN) generation in schizophrenia as a function of stimulus deviance, probability, and interstimulus/interdeviant interval. Electroencephalogr Clin Neurophysiol. 1998;108(2):143-53.

16. Donkers FCL, Schipul SE, Baranek GT, Cleary KM, Willoughby MT, Evans AM, et al. Attenuated auditory event-related potentials and associations with atypical sensory response patterns in children with autism. J Autism Dev Disord. 2015;45(2):506-23.

17. Gosselin N, Thériault M, Leclerc S, Montplaisir J, Lassonde M. Neurophysiological anomalies in symptomatic and asymptomatic concussed athletes. Neurosurgery. 2006;58(6):1151-60.

18. Justen C, Herbert C. The spatio-temporal dynamics of deviance and target detection in the passive and active auditory oddball paradigm: a SLORETA study. BMC Neurosci. 2018;19(1):25.

19. Gaetz M, Weinberg H. Electrophysiological indices of persistent postconcussion symptoms. Brain Inj. 2000;14(9):815-32.

20. Theriault M, De Beaumont L, Gosselin N, Filipinni M, Lassonde M. Electrophysiological abnormalities in well functioning multiple concussed athletes. Brain Inj. 2009;23(11):899-906.

21. Brush CJ, Ehmann PJ, Olson RL, Bixby WR, Alderman BL. Do sport-related concussions result in long-term cognitive impairment? A review of eventrelated potential research. Int J Psychophysiol. 2018;132:124-34.

22. Werff K. The application of the international classification of functioning, disability and health to functional auditory consequences of mild traumatic brain injury. Seminars in Hearing. 2016;37(03):216-32.

23. Ommaya AK, Goldsmith W, Thibault L. Biomechanics and neuropathology of adult and paediatric head injury. Br J Neurosurg. 2002;16(3):220-42.

24. Sullivan S, Friess SH, Ralston J, Smith C, Propert KJ, Rapp PE, et al. Behavioral deficits and axonal injury persistence after rotational head injury are direction dependent. J Neurotrauma. 2013;30(7):538-45.

25. Gennarelli T, editor. The centripetal theory of concussion (CTC) revisited after 40 years and a proposed new symptomcentric concept of the 
concussions. In: Proceedings of the International Research Council on the Biomechanics of Injury; 2015; Lyon, Zurich: IRCOBI.

26. Kinder HA, Baker EW, West FD. The pig as a preclinical traumatic brain injury model: current models, functional outcome measures, and translational detection strategies. Neural Regen Res. 2019;14(3):413-24.

27. Lind NM, Moustgaard A, Jelsing J, Vajta G, Cumming P, Hansen AK. The use of pigs in neuroscience: Modeling brain disorders. Neurosci Biobehav Rev. 2007;31(5):728-51.

28. Cullen DK, Harris JP, Browne KD, Wolf JA, Duda JE, Meaney DF, et al. A porcine model of traumatic brain injury via head rotational acceleration. Methods Mol Biol. 2016:8:289-324.

29. Weeks D, Sullivan S, Kilbaugh T, Smith C, Margulies SS. Influences of developmental age on the resolution of diffuse traumatic intracranial hemorrhage and axonal injury. J Neurotraum. 2014;31(2):206-14.

30. Duhaime AC. Large animal models of traumatic injury to the immature brain. Develop Neurosci. 2006;28(4-5):380-7.

31. Finnie JW. Animal models of traumatic brain injury: A review. Aust Vet $\mathrm{J}$. 2001;79(9):628-33.

32. Hagberg H, Ichord R, Palmer C, Yager JY, Vannucci SJ. Animal models of developmental brain injury: relevance to human disease. Develop Neurosci. 2002;24(5):364-6.

33. Kochanek PM, Wallisch JS, Bayır H, Clark RSBS. Pre-clinical models in pediatric traumatic brain injury_challenges and lessons learned. Childs Nerv Syst. 2017;33(10):1693-701.

34. Ryan MC, Sherman P, Rowland LM, Wijtenburg SA, Acheson A, Fieremans $E$, et al. Miniature pig model of human adolescent brain white matter development. J Neurosci Methods. 2018:296:99-108.

35. Delorme A, Makeig S. EEGLAB: an open source toolbox for analysis of single-trial EEG dynamics including independent component analysis. J Neurosci Methods. 2004;134(1):9-21.

36. Onton J, Westerfield M, Townsend J, Makeig S. Imaging human EEG dynamics using independent component analysis. Neurosci Biobehav Rev. 2006;30(6):808-22.
37. Arnfred SM, Lind NM, Moustgaard A, Hansen AK, Gjedde A. Minipig negative slow wave demonstrates target/nontarget differences in P300 paradigm. Neurolmage. 2003;20(1):587-90.

38. Korpilahti P, Lang HA. Auditory ERP components and mismatch negativity in dysphasic children. Electroencephalogr Clin Neurophysiol. 1994;91(4):256-64.

39. Arnfred SM, Lind NM, Gjedde A, Hansen AK. Scalp recordings of midlatency AEP and auditory gating in the Göttingen minipig: A new animal model in information processing research. Int J Psychophysiol. 2004;52(3):267-75.

40. Andrews RJ, Knight RT, Kirby RP. Evoked potential mapping of auditory and somatosensory cortices in the miniature swine. Neurosci Lett. 1990;114(1):27-31.

41. Albrecht R, Suchodoletz WV, Uwer R. The development of auditory evoked dipole source activity from childhood to adulthood. Clin Neurophysiol. 2000;111(12):2268-76.

42. Baillargeon A, Lassonde M, Leclerc S, Ellemberg D. Neuropsychological and neurophysiological assessment of sport concussion in children, adolescents and adults. Brain Inj. 2012;26(3):211-20.

43. Silva LAF, Magliaro FCL, Carvalho ACM, Matas CG. Cortical maturation of long latency auditory evoked potentials in hearing children: the complex P1-N1-P2-N2. CoDAS. 2017;29(4):e20160216.

44. Friess SH, Ralston J, Eucker SA, Helfaer MA, Smith C, Margulies SS. Neurocritical care monitoring correlates with neuropathology in a Swine model of pediatric traumatic brain injury. Neurosurgery. 2011;69(5):1139-47.

\section{Publisher's Note}

Springer Nature remains neutral with regard to jurisdictional claims in published maps and institutional affiliations.
Ready to submit your research? Choose BMC and benefit from:

- fast, convenient online submission

- thorough peer review by experienced researchers in your field

- rapid publication on acceptance

- support for research data, including large and complex data types

- gold Open Access which fosters wider collaboration and increased citations

- maximum visibility for your research: over $100 \mathrm{M}$ website views per year

At $\mathrm{BMC}$, research is always in progress.

Learn more biomedcentral.com/submissions 